\title{
Desvelando a construção de uma memória fonográfica do samba
}

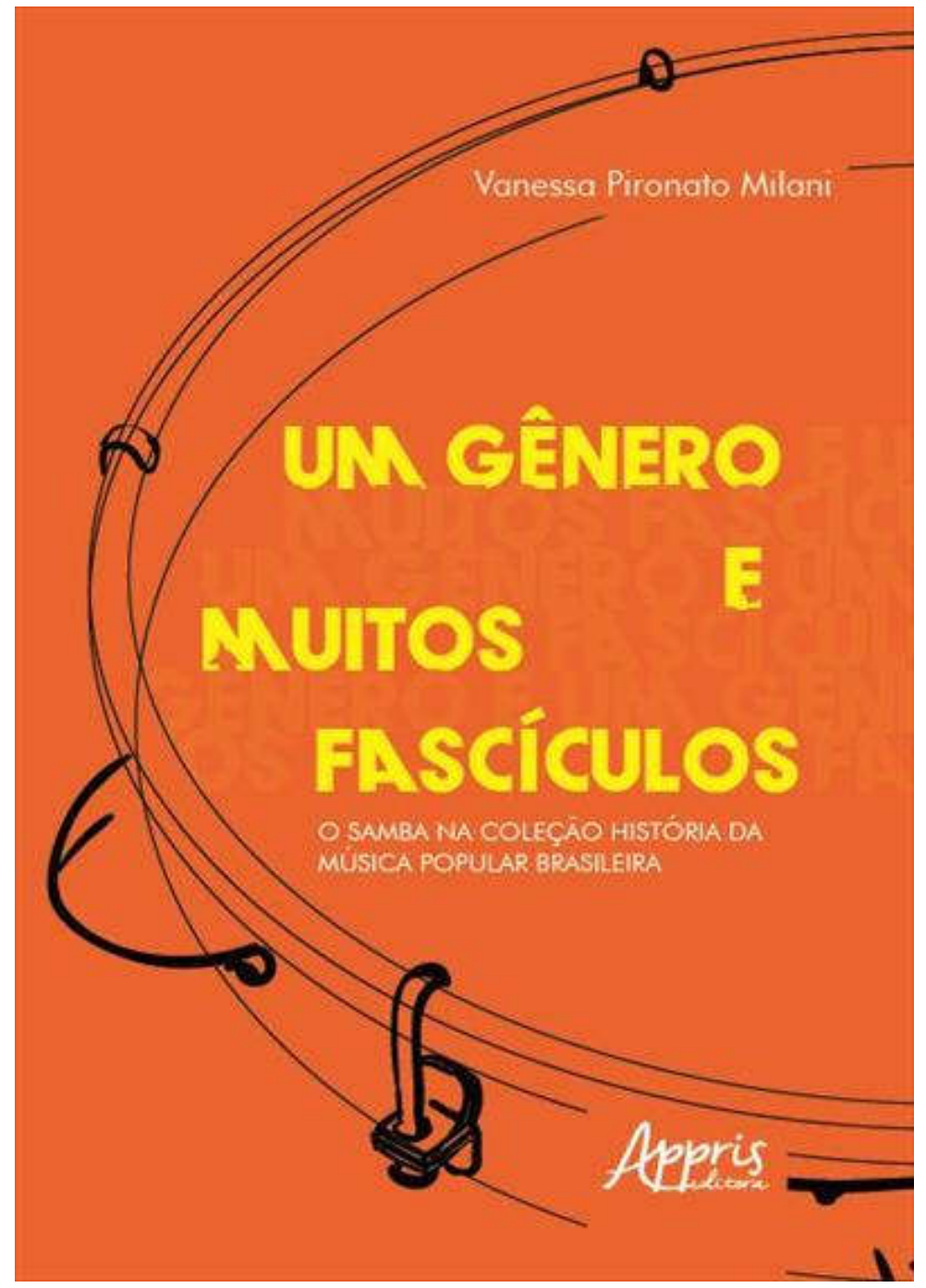

\section{Adelcio Camilo Machado}

Mestre e doutor em Música pela Universidade Estadual de Campinas (Unicamp). Professor do Departamento de Artes e Comunicação da Universidade Federal de São Carlos (UFSCar). adelcio.camilo@ufscar.br 


\title{
Desvelando a construção de uma memória fonográfica do samba
}

Unveiling the samba phonographic memory construction

\author{
Adelcio Camilo Machado
}

MILANI, Vanessa Pironato. Um gênero e muitos fascículos: o samba na coleção História da Música Popular Brasileira. Curitiba: Appris, 2019, 264 p.

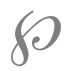

Dentre as muitas vertentes da canção popular brasileira que se consolidaram ao longo do século XX, o samba, em suas muitas manifestações, parece ocupar um lugar de destaque na produção bibliográfica, seja ela acadêmica ou não. Várias são as publicações que discorrem sobre o universo do samba, abrangendo sua história, seus personagens, seu repertório, seus estilos e suas intersecções com os cenários político, cultural e artístico. No campo da bibliografia produzida por jornalistas, críticos musicais e memorialistas, o samba tem presença marcante, tanto em textos que abordam a história da música popular brasileira de forma mais ampla ${ }^{1}$ quanto em publicações especificamente voltadas para o gênero ${ }^{2}$ ou para seus compositores e intérpretes. ${ }^{3}$

No âmbito acadêmico, estudos sobre o samba partiram de pesquisadoras e pesquisadores de diversos campos do conhecimento, com base em várias perspectivas teórico-metodológicas, que investigaram o gênero em diferentes contextos históricos, geográficos e sociais. Apenas para citar alguns exemplos, há estudos como o de Sandroni ${ }^{4}$, que se voltou para a compreensão das transformações rítmicas que se operaram no samba carioca entre as décadas de 1910 e 1930. Outras pesquisas abordaram as relações - muitas vezes conflituosas - do samba com as forças políticas, especialmente no contexto do Estado Novo. ${ }^{5} \mathrm{O}$ percurso de reconhecimento do samba como um gênero representa-

\footnotetext{
${ }^{1}$ Ver ALBIN, Ricardo Cravo. O livro de ouro da MPB. Rio de Janeiro: Ediouro, 2003; SEVERIANO, Jairo. Uma história da música popular brasileira: das origens à modernidade. São Paulo: Editora 34, 2008; TINHORÃO, José Ramos. História social da música popular brasileira. São Paulo: Editora 34, 1998.

${ }^{2}$ Ver CABRAL, Sérgio. As escolas de samba do Rio de Janeiro. Rio de Janeiro: Lumiar, 1996; FRANCESCHI, Humberto M. Samba de sambar do Estácio: 1928 a 1931. São Paulo: Instituto Moreira Salles, 2010; SOUZA, Tárik de. Tem mais samba: das raízes à eletrônica. São Paulo: Editora 34, 2003; TINHORÃO, José Ramos. O samba agora vai: a farsa da música popular brasileira no exterior. Rio de Janeiro: JCM, 1969.

${ }^{3}$ Ver CABRAL, Sérgio. No tempo de Almirante: uma história do rádio e da MPB. Rio de Janeiro: Francisco Alves, 1990; CASTRO, Ruy. Carmen: uma biografia. São Paulo: Companhia das Letras, 2005; MÁXIMO, João e DIDIER, Carlos. Noel Rosa: uma biografia. Brasília: Editora UnB/Linha Gráfica Editora, 1990; RANGEL, Lúcio. Sambistas e chorões: aspectos e figuras da música popular brasileira. São Paulo: Livraria Francisco Alves, 1962.

${ }_{4}^{4}$ SANDRONI, Carlos. Feitiço decente: transformações do samba no Rio de Janeiro (1917-1933). 2. ed. ampl. Rio de Janeiro: Zahar, 2012.

${ }^{5}$ Ver MATOS, Cláudia Neiva de. Acertei no milhar: malandragem e samba no tempo de Getúlio. Rio de Janeiro: Paz e Terra, 1982; PARANHOS, Adalberto. Os desafinados: sambas e bambas no "Estado Novo". São Paulo: Intermeios/CNPq/Fapemig, 2015; VASCONCELLOS, Gilberto e SUZUKI JR., Matinas. A
} 
tivo da nacionalidade brasileira ${ }^{6}$ também ocupou um espaço de destaque na produção bibliográfica; no desdobramento disso, as investigações discutiram sobre seu vínculo com as ideias de "tradição" e "autenticidade" 7 , bem como o papel da indústria fonográfica nesse processo. ${ }^{8}$ Existem ainda estudos voltados para as manifestações musicais e culturais das quais o samba se originou', para suas aproximações e distanciamentos em relação à cultura afrobrasileira ${ }^{10} \mathrm{e}$, em particular, para suas relações com a comunidade afro-baiana que residia no Rio de Janeiro no início do século XX. ${ }^{11}$ Somam-se a isso pesquisas sobre produções ligadas ao samba que tiveram participação expressiva no mercado musical de suas épocas. ${ }^{12}$

É nesse amplo quadro bibliográfico que se situa o livro da historiadora Vanessa Pironato Milani, derivado de seu mestrado realizado na Unesp de Assis sob orientação de Áureo Busetto. De saída, a autora se defrontava com o desafio de definir um recorte para sua pesquisa, de modo que o estudo de seu objeto pudesse trazer contribuições em torno de uma temática intensamente investigada. A leitura da obra mostra que tal desafio foi superado de forma bastante exitosa. Milani inseriu seu estudo no campo da construção da memória a respeito do samba e, para tanto, escolheu como objeto a primeira e a terceira edições da Coleção História da Música Popular Brasileira, da Editora Abril, lançadas respectivamente entre 1970 e 1972, e entre 1982 e 1984 . Tratava-se de uma coleção fonográfica que se propunha, no conjunto de seus fascículos, a representar "a história" da música popular brasileira. A partir daí, ela verificou as maneiras pelas quais o samba ali foi retratado.

Ao se debruçar sobre os fascículos, a autora leva em consideração uma diversidade de elementos: o repertório selecionado, as letras das canções, os compositores e intérpretes presentes, bem como as imagens e os textos que integram os encartes. Além disso, extrapolando os fascículos propriamente ditos, ela observou igualmente as peças publicitárias divulgadas em periódicos do período, com base nos quais aprofundou a análise sobre os ideários subjacentes à coleção.

O livro é dividido em três capítulos, precedidos por uma introdução e seguidos pelas considerações finais, além de contar com um prefácio do histo-

\footnotetext{
malandragem e a formação da música popular brasileira. In: FAUSTO, Boris (dir.). História geral da civilização brasileira - III - O Brasil republicano: economia e cultura (1930-1964). 3. ed. São Paulo: Difel, 1984.

${ }^{6}$ Ver VIANNA, Hermano. O mistério do samba. 2. ed. Rio de Janeiro: Zahar, 2012.

${ }^{7}$ Ver NAPOLITANO, Marcos. A síncope das ideias: a questão da tradição na música popular brasileira. São Paulo: Fundação Perseu Abramo, 2007; FERNANDES, Dmitri Cerboncini. A inteligência da música popular: a "autenticidade" no samba e no choro. Tese (Doutorado em Sociologia) - USP, São Paulo, 2010.

${ }^{8}$ Ver FENERICK, José Adriano. Nem do morro, nem da cidade: as transformações do samba e a indústria cultural (1920-1945). São Paulo: Annablume/Fapesp, 2005.

9 Ver CUNHA, Fabiana Lopes da. Samba carioca e carnaval: sonoridades, identidade, urbes e imaterialidade. In: GARCIA, Tânia da Costa e TOMÁS, Lia (orgs.). Música e política: um olhar transdisciplinar. São Paulo: Alameda, 2013; idem, Sonoridades carnavalescas e identidades: sons, ritmos e diferentes festas no Rio de Janeiro em fins do século XIX e início do século XX. In: GARCIA, Tânia da Costa e FENERICK, José Adriano (orgs.). Música popular: história, memória e identidades. São Paulo: Alameda, 2015.

${ }^{10}$ Ver LOPES, Nei. O negro no Rio de Janeiro e sua tradição musical: partido-alto, calango, chula e outras cantorias. Rio de Janeiro: Pallas, 1992; idem, Partido-alto: samba de bamba. Rio de Janeiro: Pallas, 2005.

${ }^{11}$ Ver MOURA, Roberto. Tia Ciata e a pequena África do Rio de Janeiro. Rio de Janeiro: Funarte, 1983.

12 Ver MACHADO, Adelcio Camilo. Quem te viu, quem te vê: o samba pede passagem para a década de 1970. Dissertação (Mestrado em Música) - Unicamp, Campinas, 2011; TROTTA, Felipe. O samba e suas fronteiras: "pagode romântico" e "samba de raiz" nos anos 1990. Rio de Janeiro: Editora UFRJ, 2011.
} 
riador José Adriano Fenerick. No primeiro capítulo, a autora traz um mapeamento histórico sobre as distintas práticas e concepções acerca das coleções. Dentre as muitas informações levantadas por Milani, encontra-se a ideia de que as coleções se colocam como uma forma de preservar e dar "eternidade" aos objetos coletados - algo que, como a obra progressivamente revela, parece se manter no ideário da coletânea examinada. Ainda nesse capítulo, deparamo-nos com informações sobre o desenvolvimento da indústria cultural no Brasil e a posição da Editora Abril nesse contexto. São apresentadas as primeiras análises sobre a Coleção História da Música Popular Brasileira, focalizando especialmente os aspectos visuais das edições e os perfis dos colaboradores dos textos dos encartes dos discos. A pesquisadora procura, então, explicitar como algumas estratégias publicitárias da Abril Cultural visavam minorar o caráter mercantil da coleção, buscando identificá-la como um produto especificamente "cultural". Por fim, Milani traça um panorama dos debates estéticos que se travavam na década de 1960 sobre a canção popular brasileira, com destaque para a ideia de "linha evolutiva", e evidencia de que maneira tais discussões impactaram a seleção do repertório e dos artistas que figurariam na coleção.

O segundo capítulo expõe um detalhamento dos fascículos investigados. Milani elenca inicialmente cada um dos compositores presentes, passando depois para os intérpretes e, por último, enfoca os jornalistas e críticos musicais que publicaram textos nos encartes; nesse ponto, os destaques ficaram para Tárik de Souza e José Ramos Tinhorão, que colaboraram de forma mais contínua com essa atividade. Ao discorrer sobre cada um desses agentes compositores, intérpretes ou críticos -, o capítulo não se resume a uma análise sobre sua presença na coletânea, mas mobiliza uma grande quantidade de informações sobre suas respectivas trajetórias e perspectivas. Nesse passo, o texto se coloca como uma fonte muito significativa para leitores que não estão familiarizados com a história do samba.

Já no terceiro capítulo, a historiadora discute como as ideias de "tradição" e "autenticidade" se expressaram nas duas versões da coleção. De início, a análise se direciona para os textos dos encartes e, na sequência, se detém nas letras dos sambas. $\mathrm{Na}$ esteira disso, são exploradas de diferentes maneiras a complexidade de que se reveste a alegada oposição entre a "autenticidade" do samba e seu caráter mercadológico. Isso aparece, por exemplo, quando a historiadora discute a figura de Ary Barroso (p. 177 e 178), sempre lembrado como um ferrenho defensor das "tradições" do samba, mas que teve ampla penetração nos meios de comunicação de massa, inclusive no exterior.

Nesse capítulo, dois subcapítulos chamam a atenção. No primeiro deles, a autora continua examinando as letras das canções, porém sem se prender à questão da "tradição", e sim verificando de que modo os sambas registravam problemas sociais. A pesquisa ressalta que sambas com essa temática, praticamente ausentes da primeira edição da coleção, foram recorrentes na terceira. Diante disso, Milani cogita a possibilidade de que tal fato tenha correspondência com a própria atenuação do caráter repressor da ditadura militar num momento em que a luta por liberdades democráticas falava mais alto. Nesse embalo, ela se concentra em alguns sambas que faziam críticas ao regime militar e reverberavam o avanço do movimento pela anistia. 
No outro subcapítulo, a historiadora examina os fascículos da coleção pela perspectiva dos estudos de gênero. De cara, adverte para a pouca presença de fascículos dedicados especificamente a mulheres: dois, na primeira edição, e três, na terceira, sendo que, em todos os casos, as mulheres dividiam espaço com compositores homens. Por decorrência, como salienta Milani, a presença das sambistas mulheres na coleção se dava, sobretudo, na condição de intérpretes de canções compostas por homens. Na sequência, ela se atém às letras dos sambas para verificar as representações sociais sobre as mulheres ali inscritas. Em linhas gerais, o que se constata é que diversas composições retratam um perfil de mulher submissa ao homem. Porém, apesar da predominância de compositores homens na coleção, Milani localizou sambas que se referiam a mulheres que se afastavam desses padrões, notadamente na terceira versão. Tais canções são entendidas pela autora como um sintoma das lutas sociais das mulheres visando à sua emancipação.

Entre as muitas contribuições da sua pesquisa, a autora explicita que, apesar de algumas divergências entre seus colaboradores, a coleção reitera uma narrativa, relativamente hegemônica, em torno do samba e de sua história, que o vincula às ideias de identidade nacional e de "tradição", ao mesmo tempo em que o situa como eixo central sobre o qual se desenvolveu uma certa "linha evolutiva" da música popular brasileira. Como já demonstrado em vários estudos, essa narrativa, de caráter homogeneizador, oblitera as muitas fissuras e tensões que permearam a história do samba, incluindo seus diferentes atores sociais, seus distintos espaços de produção, fruição e circulação, e os diversos projetos estéticos e políticos dos quais se aproximou. ${ }^{13}$ Tal caráter foi apontado pela própria autora, quando afirma que a coleção "buscava firmar entre seus leitores/ouvintes um ideal de música popular brasileira que conseguisse conciliar os diferentes projetos musicais que se pretendia para o Brasil" (p. 159).

Nessa perspectiva, a leitura do livro suscita uma questão: a quem interessa a construção dessa narrativa sobre a história do samba, que o apresenta como conectado à "tradição" e destituído de conflitos? Como se sabe, a história é um campo de lutas, no qual se confrontam diferentes memórias, e o estabelecimento de certas narrativas hegemônicas costuma estar associado ao campo do poder. $^{14}$ Por isso parece relevante lembrar que a primeira edição da coleção foi lançada entre 1970 e 1972, portanto, no contexto mais repressivo da ditadura militar. Tratava-se de um governo que, do ponto de vista político,

\footnotetext{
${ }^{13}$ A título de ilustração, sabe-se que a passagem dos "primitivos" do samba, como Donga, Sinhô e João da Bahiana, para a geração dos sambistas do Estácio é bastante complexa e dificilmente pode ser analisada apenas sob o prisma da continuidade. Na contramão desse discurso um tanto homogeneizador, Carlos Sandroni (op. cit.) acentuou como essas duas práticas associavam-se a paradigmas rítmicos diferenciados. José Adriano Fenerick (op. cit.), por sua vez, sublinha como o samba praticado no bairro da Cidade Nova, no Rio de Janeiro, se ligava a práticas inclusive religiosas da comunidade afro-baiana, algo que não mais acontecia no samba do Estácio. Outra situação se refere ao samba produzido e/ou consumido pelos setores médios da sociedade, principalmente pela população branca. Para a coleção, como exposto por Milani, tal tema não é problematizado, o que se observa, por exemplo, no fato de Noel Rosa haver sido o escolhido como primeiro fascículo e de ser apontado como mais um dos "legítimos" representantes do samba. Todavia, para autores como Muniz Sodré (citado à p. 184), a realização do samba por indivíduos brancos caracterizaria um processo de expropriação de práticas culturais da população negra.

${ }^{14}$ Para uma discussão adensada sobre o assunto, ver FOUCAULT, Michel. Arqueologia do saber. 7. ed. Rio de Janeiro: Forense Universitária, 2010; LE GOFF, Jacques. História e memória. 5. ed. Campinas: Editora da Unicamp, 2003.
} 
tentava minar quaisquer expressões de dissenso por intermédio da censura e da violência, e que, ideologicamente, era ufanista e defensor das "tradições". A menção a esses elementos não é feita com o intuito de estabelecer uma relação mecânica entre o governo militar e a coleção, como se o primeiro determinasse a segunda. Seja como for, não deixa de ser pertinente, a nosso ver, reconhecer a existência de algum grau de compatibilidade de valores, ou seja, pode-se pensar que as ideias de "tradição" e "brasilidade", gestadas no âmbito da canção popular por segmentos das esquerdas e que norteavam a concepção da coleção, talvez não incomodassem os ocupantes do poder estatal.

Acrescente-se que a iniciativa da coleção partiu de uma grande empresa do setor editorial, o que reforça a ideia de que as relações entre o objeto do livro e a política brasileira da época precisam ser analisadas com a mediação da indústria cultural. Afinal, as décadas de 1960 e de 1970 foram períodos de acelerado desenvolvimento no mercado brasileiro de bens simbólicos e isso se ocorreu sob as asas de um governo ditatorial. Assim, não é de se estranhar que essa indústria se disponha a "vender" acima de tudo o consenso, em vez do conflito.

De volta às relações entre a coleção e a esfera política, é admissível, por hipótese, cogitar que a quantidade maior de regravações da terceira edição, lançada na primeira metade da década de 1980, seja sintomática de um arrefecimento de determinados ideários que norteavam o regime militar. Em outras palavras, ao mesmo tempo em que a defesa da "tradição" se enfraquecia, surgia uma nova edição da coleção menos preocupada em "resgatar" as "grandes gravações do passado" e mais empenhada em atualizar aquele repertório.

Tais reflexões se colocam como hipóteses para se pensar sobre outras relações entre a primeira e a terceira edições da coleção e seus respectivos contextos históricos, dando continuidade à pesquisa de Vanessa Pironato Milani. Independentemente disso, o seu livro oferece uma sólida contribuição para os estudos acerca do samba. Para leitores e leitoras que acompanham a produção bibliográfica sobre esse gênero, o trabalho da historiadora se mostra muito bem delimitado, possuindo respaldo teórico para levar adiante sua investigação e estabelecer pertinentes conexões com os referenciais já disponíveis. Por outro lado, para quem não é conhecedor do tema, a obra pode ser uma significativa porta de entrada, pois, para além da análise da coleção, incorpora preciosas informações sobre o universo do samba.

Resenha recebida em 30 de agosto de 2021. Aprovada em 22 de setembro de 2021. 